\title{
ПРИКЛАДНА СПРЯМОВАНІСТЬ ВИКЛАДАННЯ ВИЩОЇ МАТЕМАТИКИ СТУДЕНТАМ ЕКОНОМІЧНОГО ПРОФІЛЮ ВНЗ
}

У статті представлено основи прикладної спрямованості викладання вищої математики майбутнім економістам. Запропоновано систему професійно орієнтованих математичних задач з економічною складовою, яка попередньо потребує побудови необхідної математичної моделі процесу, вибору для цъього необхідного математичного апарату, методу та способу розв'язання. Визначено функиї системи задач прикладної спрямованості.

Ключові слова: задачі з економічним змістом, математичні моделі, економічне і математичне мислення.

Підготовка спеціалістів економіки передбачає грунтовні знання з вищої математики та вміння їх застосовувати в майбутній професійній діяльності. Дедалі зростає роль формально-логічного апарату математики, математичного моделювання, статистично-ймовірнісних методів у мікро та макроекономіці. Математичні закономірності широко використовуються в економіці сучасного виробництва, в конкретних економічних процесах і явищах.

Постановка проблеми. Вища математика відіграє особливу роль у соціально-економічних дослідженнях. Вона є однією з найуніверсальніших мов науки. Сучасний фахівець в галузі економіки повинен уміти аналізувати поточні економічні процеси, бути здатним до вирішення виробничих та управлінських завдань, розуміти роль і місце математики у сфері економіки. Одним із способів підвищення якості підготовки фахівців економічного профілю $є$ забезпечення прикладної спрямованості викладання вищої математики. Основним засобом прикладної спрямованості навчання вищої математики студентів економічних спеціальностей є задачі ситуаційного характеру, тобто задачі з економічним змістом. Розв'язання подібних задач "студентами-економістами" є важливим засобом формування математичних знань і основною формою навчальної роботи в процесі навчання вищої математики.

Аналіз основних досліджень. Загальні проблеми математичної підготовки студентів економічних спеціальностей вищих навчальних закладів висвітлені у працях Н. Л. Ванжі, Г.Я. Дутки, Л. І. Нічуговської, Ю.М.Ткач, О. Г. Фомкіної та інших. Питання розв'язування задач економічного змісту засобами математики досліджували О. О. Аршава, Л. С. Межейникова, В. М. Монахов та інші. Окремі питання професійної спрямованості вивчення математичних дисциплін на рівні вищих навчальних закладів висвітлювали В. І. Клочко, Т. В. Крилова, В. В. Пак та інші. Дисертаційні дослідження В.Г. Скатецького "Наукові основи професійної спрямованості викладання математики студентам нематематичних спеціальностей", Крилової Т. В. "Наукові основи навчання математики студентів нематематичних спеціальностей", Фомкіної О. Г. "Методична система проведення практичних занять з математики зі студентами економічних спеціальностей" спрямовані на розв'язання проблем методики навчання математики студентів нематематичних спеціальностей, в тому числі й економічних.

Окреслення невирішених питань. 3 кожним роком математичні методи все більше проникають в усі сфери життя суспільства. Високий рівень математичної підготовки - необхідна умова успішності і затребуваності випускника на ринку праці. Працедавці потребують від молодих фахівців відповідальності, здатності логічно мислити, аналізувати та прогнозувати результати своєї діяльності. Математика, як найкраще сприяє формуванню таких здібностей. У студентів формується системність мислення і дій, здатність до аналізу, абстрагування, систематизації. Проте, часто, студенти ставлять питання : навіщо їм математика, як вона знадобиться їм в подальшому житті, як знання формул і теорем допоможуть у вибраній спеціальності? Відповісти на такі запитання, а також показати студентам зв'язок математики 3 їх майбутньою професією, змінити їх емоційно-чуттєве відношення до предмету, надає можливість розв'язання задач прикладного характеру. Прикладні задачі - задачі з різних сфер життя, не пов'язаних з математикою, але ті, що розв'язуються за допомогою математичних методів.

Формулювання мети статті. Обгрунтувати необхідність прикладної спрямованості навчання вищої математики студентів економічних спеціальностей за допомогою застосування математичного 
моделювання, що забезпечує як змістовий, так i методологічний зв'язок між дисциплінами математичного та економічного профілю.

Основний зміст. Часто буває так, що студент добре засвоює формальні навички, але виникають проблеми, коли потрібно застосувати ці навички до умінь розв'язувати задачі прикладного характеру, які попередньо потребують побудови необхідної математичної моделі процесу, вибору для цього необхідного математичного апарату, методу та способу розв'язання. Саме цим визначається математична культура сучасного економіста. Слід зазначити і те, що зміст формальних задач недостатньо враховує сьогодення, що висувається до математичної освіти студентів економічної спрямованості [1]. Отже, ефективність навчання студентів економічних спеціальностей багато в чому залежить від відбору професійно орієнтованих математичних задач з економічною складовою, від способу їх конструювання і методики роботи 3 ними. Під професійно оріснтованими математичними задачами 3 економічною складовою ми розуміємо задачі, зміст яких пов'язаний з об'єктами і процесами майбутньої професійної діяльності студента, a їх дослідження за допомогою математичного апарату сприяє усвідомленому застосуванню математичних знань під час вивчення циклу спеціальних дисциплін та формуванню професійної компетентності майбутнього економіста.

Система задач повинна реалізовувати внутрішньопредметний аспект прикладної спрямованості навчання. 3 урахуванням вищевикладеного використання такої системи задач виконує наступні функції: розвивальну, що спрямована на розвиток економічного і математичного мислення; навчальну, що спрямована на формування знань і умінь використання математичного апарату для аналізу економічних ситуацій; виховну, що спрямована на розвиток пізнавального інтересу та самостійності студентів; контролюючу, що спрямована на встановлення рівня засвоєння студентами запропонованого матеріалу, їх здібностей до самостійного вивчення окремих тем курсу вищої математики.

У процесі навчання студенти повинні опанувати велику кількість дисциплін різної спрямованості. Але не рекомендується розглядати кожну дисципліну окремо й не враховувати їі взаємозв'язок з іншими дисциплінами. У зв’язку з цим варто було б при розробці робочих програм дисциплін і плануванні курсів приділяти особливу увагу тим аспектам і навичкам, які студенти повинні вже мати на підставі раніше вивченого матеріалу, а також окреслити коло питань і задач, при вивченні яких буде використовуватися матеріал даної дисципліни. Це дозволить ставити більш конкретні задачі, підвищити мотивацію вивчення дисциплін і дати відповідь на вічні запитання всіх студентів "навіщо нам це потрібно?" і "де це буде використовуватися?". Такий підхід може стимулювати викладачів враховувати при розробці курсу дисципліни не тільки свою суб'єктивну думку про те, як саме будувати курс та більш якісно використовувати раніше отримані студентами знання, а й також необхідність використання отриманих знань надалі в навчанні [2].

Багаторічний досвід викладання вищої математики студентам економічних спеціальностей різних форм навчання та спілкування 3 висококваліфікованими фахівцями надає можливість авторам стверджувати, що внаслідок різноманітних об'єктивних та суб'єктивних причин значна частина студентів потребує удосконалення початкового математичного рівня для успішного навчання у ВНЗ.

Для розв'язання різних економічних задач необхідною складовою професійної діяльності сучасного економіста $€$ використання математичного апарату. Дослідження таких задач вимагає застосування математичного моделювання економічних об'єктів, явищ і процесів, використання кількісних методів опрацювання даних, різних обчислювальних засобів.

Найбільш розповсюдженими є матричні моделі в економіці, які успішно застосовуються під час аналізу й плануванні виробництва. Такі моделі доцільно застосовувати при визначенні балансу виробництва та розподілу продукції між різними галузями, складанні міжгалузевого балансу виробництва продукції для окремих економічних районів, розрахунках технолого-економічних планів для підприємств. Матричні моделі зручні для аналізу, оскільки вони у простій і наочній формі відображають властивості різних об'єктів, особливо, де має місце баланс надходження і витрат матеріальних цінностей, енергії вартості, інформації, причому така залежність між ними є лінійною. Одним 3 таких є метод аналізу економіки "витрати - випуск". Метод відображає матричні (балансові) моделі, що побудовані за шаховою схемою і наочно ілюструють взаємозв'язок витрат і прибутку виробництва. При вивченні матричного числення слід звернути увагу студентів, що за допомогою додавання матриць послідовні ланки виробництва пов'язуються в єдиний взаємопов'язаний комплекс, а для одночасного відображення виробничо-технологічної і організаційної структури використовують властивості добутку матриць.

На основі теоретичних положень аналітичної геометрії на площині побудована математична модель рівноваги ринку, в якій основним є співвідношення між двома величинами: ціною одиниці товару $p$ та обсягом товару на ринку $q$. Ціну одиниці товару $p$ та обсяг товару на ринку $q$ потрібно розглянути як впорядковану пару чисел $(p ; q)$ і поставити їй у відповідність на площині точку $(p ; q)$. Функцію $S=S(p)$ називають функцією пропозиції товару, а функцію $g=g(p)$-функцією попиту товару. 
При побудові математичної моделі рівноваги доходів і збитків компанії використовується рівняння прямої на площині.

У процесі викладання розділу "Аналітична геометрія" доцільно розглянути приклади про аналіз збитковості та прибутковості виробництва, рентабельність транспортних перевезень, співвідношення між затратами праці і виробничих фондів, які виражаються лініями першого і другого порядків. Зокрема, якщо загальні витрати $T C(X)$ і загальний прибуток $T R(X)$ лінійно залежать від обсягу $x$ виробленої продукції: $T C(X)=k_{1} x+b_{1}, T R(X)=k_{2} x \quad$ то точка переходу $\quad x_{0}=\frac{b_{1}}{k_{2}-k_{1}}$ від збитковості до прибутковості визначається розв'язком рівняння $T C(X)=T R(X)$ і $є$ точкою перетину прямих, що відображають залежність витрат і доходу від обсягу продукції.

Диференціальне числення - це математичний апарат, що широко застосовується для економічного аналізу. В економіці дуже часто потрібно знайти оптимальне значення деякого показника (наприклад, максимальний прибуток, мінімальні витрати, найвищу продуктивність праці). Кожен показник $\epsilon$ функцією однієї чи декількох змінних. Такі задачі утворюють клас задач в економіці, розв'язання яких пов'язане з використанням методів диференціального числення.

Задачі про обчислення граничних витрат виробництва, граничної корисності, граничного прибутку можна дістати з відповідних економічних функцій шляхом диференціювання.

Важливим напрямом застосування диференціального числення в економіці є введення на його базі поняття еластичності функції. Еластичністю функції $E_{x}(y)$ називають границю відношення відносного приросту функції $y$ до відносного приросту змінної $x$ при $\Delta x \rightarrow 0$

$$
E_{x}(y)=\lim _{\Delta x \rightarrow 0}\left(\frac{\Delta y}{y} \div \frac{\Delta x}{x}\right)=\frac{x}{y} y^{\prime}
$$

Еластичність застосовують під час аналізу попиту та пропозиції.

Інтегральне числення дає змогу розв'язати обернену задачу, знайти дану економічну функцію за відомою граничною функцією.

Розглядаючи задачі, що призводять до використання визначеного інтегралу, вважаємо, що потрібно звернути увагу студентів на застосування визначеного інтегралу у фінансових задачах, задачах реалізації товарів. Визначений інтеграл дорівнює обсягу виробленої продукції підприємством (фірмою) 3 продуктивністю праці $f=f(t)$ за інтервал часу $[0 ; T]$, тобто $q=\int_{0}^{T} f(t) d t$. За допомогою визначеного інтегралу можна обчислити середні значення економічних функцій, визначити приріст капіталу за відомими інвестиціями, ступінь нерівномірності розподілу доходів населення.

Диференціальні рівняння застосовуються в моделях економічної динаміки, в яких відображається не тільки залежність змінних від часу, але й їх взаємозв’язок у часі.

Студентам можна запропонувати задачу в якій потрібно знайти закон зміни вартості устаткування, якщо початкова його вартість дорівнює $S_{0}$, а швидкість знецінення устаткування внаслідок його амортизації пропорційна його фактичній вартості. Розв'язання цієї задачі зводиться до диференціального рівняння. Нехай $S(t)$ - вартість устаткування у момент часу $t$. Тоді $S^{\prime}(t)$ - швидкість зміни вартості внаслідок амортизації. Згідно з умовою задачі, отримуємо наступне рівняння $S^{\prime}(t)=-k S(t)$, де $k>0$ коефіцієнт пропорційності. Знак " -" говорить про зменшення вартості устаткування з часом. Початкова вартість $S_{0}$ задає початкову умову для отриманого рівняння. Таким чином, отримаємо задачу Коші: знайти частинний розв'язок диференціального рівняння $S^{\prime}(t)=-k S(t)$, якщо $S(0)=S_{0}$ Під час розв'язання такої задачі ми спрямовуємо діяльність студентів на побудову математичної моделі реальної життєвої ситуації.

Оскільки ринкові відносини часто супроводжуються випадковими явищами i процесами, тому фактори впливу на результат дії мають ймовірнісний характер. В такій ситуації результат дії потрібно передбачувати i розраховувати ступені його ризиків. Саме в розділі "Теорія ймовірностей i математична статистика" закладаються базові знання для таких передбачень і розрахунків. Під час викладання випадкових подій, випадкових величин, функцій випадкового аргументу та елементів математичної статистики достатньо обмежитися розв'язуванням простих практичних задач, в яких використовуються ці поняття і методи: розрахунок імовірностей банкрутства фірм, своєчасного повернення кредитів банком, а також характеристики генеральної сукупності і т. п. Особливу увагу слід 
звернути на граничні теореми теорії ймовірностей, які надають можливість зробити майже вірогідні передбачення розвитку випадкових подій і процесів.

Висновки. Майбутній економіст повинен володіти методами математики, які використовуються в економічних дослідженнях. Це сприятиме кращому використанню знань під час вибору математичних методів і побудови економіко-математичних моделей. Знайомство 3 різними типами економікоматематичних моделей в процесі роботи з професійно орієнтованими задачами надає можливість сформувати у студентів переконання про значущість математики в їх майбутній професійній діяльності.

\section{СПИСОК ВИКОРИСТАНИХ ДЖЕРЕЛ ТА ЛІТЕРАТУРИ}

1. Фомкіна О. Г. Удосконалення методики навчання математики в економічному вузі : шляхи, форми i засоби, перспективи : [монографія] / О. Г. Фомкіна. - Полтава : РВВ ПУСКУ, 2008. - 122 с.

2. Думанська Т. В. Складові математичної компетентності бакалаврів економіки / Т. В. Думанська // Збірник наукових праць молодих вчених Кам'янець-Подільського національного університету імені Івана Огієнка. Кам'янець-Подільський : Кам'янець-Подільський національний університет імені Івана Огієнка, 2014. Вип. 7. - С. 135-136.

3. Бондаренко 3. В. Співвідношення між фундаментальною і професійною спрямованістю навчання вищої математики майбутніх інженерів / 3. В. Бондаренко, С. А. Кирилащук // Наукові записки. - Випуск 8. Частина 2. - Серія : Проблеми методики фізико-математичної і технологічної освіти. - Кіровоград : РВВ КДПУ ім. В. Винниченка, 2015. - С. 3-8.

4. Гончарова О.М. Міжпредметний підхід до навчання студентів економічних спеціальностей/ О. М. Гончарова // Вісник Черкаського університету імені Богдана Хмельницького. Педагогічні науки. Черкаси : Черкаський університет імені Богдана Хмельницького, 2011. - Частина II, Випуск 199. - С. 6-10.

5. Дутка Г. Я. Формування вмінь студентів розв'язувати прикладні задачі при навчанні математики в коледжах економічного профілю : дис. ... канд. пед. наук : 13.00.02 / Ганна Яківна Дутка. - К., 1998. - 187 с.

6. Кирилащук С. А. Педагогічні умови формування інженерного мислення студентів технічних університетів у процесі навчання вищої математики : автореф. дис. ... канд. пед. наук : $13.00 .04 /$ Кирилащук Світлана Анатоліївна ; Вінниц. держ. пед. ун-т ім. М. Коцюбинського. - Вінниця, 2010. - 20 с.

7. Ткач Ю. М. Професійна спрямованість навчання вищої математики у системі економічної освіти/ Ю. М. Ткач // Дидактика математики : проблеми і дослідження : [міжнародний збірник наукових робіт]. Вип. 35. - Донецьк : Вид-во ДонНУ, 2011. - С. 93-97.

\section{REFERENCES (TRANSLATED \& TRANSLITERATED)}

1. Fomkina O. H. Udoskonalennia metodyky navchannia matematyky v ekonomichnomu vuzi : shliakhy, formy i zasoby, perspektyvy [Improvement of Methodology of Studies of Mathematics in Economic Institution of Higher Learning : Ways, Forms and Facilities, Prospects] : [monohrafiia] / O. H. Fomkina. - Poltava : RVV PUSKU, 2008. $-122 \mathrm{~s}$.

2. Dumanska T. V. Skladovi matematychnoi kompetentnosti bakalavriv ekonomiky [Constituents of Mathematical Competence of Bachelors of Economy]/T.V. Dumanska//Zbirnyk naukovykh prats' molodykh vchenykh Kamianets'-Podilskoho natsional'noho universytetu imeni Ivana Ohiienka [Collection of Young Scientists' Scientific Works of Kamianets-Podilskyi Ivan Ohienko National University]. - Kamianets'-Podils'kyi : Kamianets-Podils'kyi natsional'nyi universytet imeni Ivana Ohiienka, 2014. - Vyp. 7. - S. 135-136.

3. Bondarenko Z. V. Spivvidnoshennia mizh fundamental'noiu i profesiinoiu spriamovanistiu navchannia vyshchoi matematyky maibutnikh inzheneriv [Betweenness by the Fundamental and Professional Orientation of Studies of Higher Mathematics of Future Engineers] / Z. V. Bondarenko, S. A. Kyrylashchuk // Naukovi zapysky [Academic Writings]. - Vypusk 8. - Chastyna 2. - Seriia : Problemy metodyky fizyko-matematychnoi i tekhnolohichnoi osvity. - Kirovohrad : RVV KDPU im. V. Vinnichenka, 2015. - S. 3-8.

4. Honcharova O. M. Mizhpredmetnyi pidkhid do navchannia studentiv ekonomichnykh spetsial'nostei [Intersubject Approach to Learning of Students of Economic Specialities]/O. M. Honcharova//Visnyk Cherkaskoho universytetu imeni Bohdana Khmelnytskoho. Pedahohichni nauky [Cherkasy Bohdan Khmelnytsky National University Journal]. - Cherkasy : Cherkas'kyi universytet imeni Bohdana Khmelnytskoho, 2011. - Chastyna II, Vypusk 199. - S. 6-10.

5. Dutka H. Ia. Formuvannia vmin' studentiv rozv'iazuvaty prykladni zadachi pry navchanni matematyky v koledzhakh ekonomichnoho profiliu [Forming of Abilities of Students to Decide the Applied Tasks at the Studies of Mathematics in the Colleges of Economic Profile] : dys. ... kand. ped. nauk : 13.00.02 / Hanna Yakivna Dutka. - K., 1998. $-187 \mathrm{~s}$.

6. Kyrylashchuk S. A. Pedahohichni umovy formuvannia inzhenernoho myslennia studentiv tekhnichnykh universytetiv u protsesi navchannia vyshchoi matematyky [Pedagogical Terms of Forming of the Engineering Thinking of Students of Technical Universities in the Process of Studies of Higher Mathematics] : avtoref. dys. ... kand. ped. nauk : 13.00.04 / Kyrylashchuk Svitlana Anatoliivna ; Vinnyts'. derzh. ped. un-t im. M. Kotsiubynskoho. - Vinnytsia, 2010. - $20 \mathrm{~s}$.

7. Tkach Iu. M. Profesiina spriamovanist' navchannia vyshchoi matematyky u systemi ekonomichnoi osvity [Professional Orientation of Studies of Higher Mathematics in the System of Economic Formation]/ Iu. M Tkach // Dydaktyka matematyky : problemy i doslidzhennia [Didactics of Mathematics: Problems and Researches] : [mizhnarodnyi zbirnyk naukovykh robit]. - Vyp. 35. - Donets'k : Vyd-vo DonNU, 2011. - S. $93-97$. 


\section{Бондаренко З. В., Кирилацук С. А. Прикладная направленность преподавания высшей математики студентам экономического профиля ВУЗа.}

В статье представлены основы профессиональной направленности преподавания математики будущим экономистам. Предложена система профессионально ориентированных математических задач с экономической составляющей, которая предварительно нуждается в построении необходимой математической модели прочесса, выбора необходимого математического аппарата, выбора метода или способа решения задачи. Определены функции системы задач прикладной направленности.

Ключевые слова: задачи с экономическим содержанием, математические модели, экономическое и математическое мышление.

\section{Bondarenko Z. V., Kirilashchuk S. A. Applied Orientation of Teaching Higher Mathematics for Students of Higher Educational Establishment with Economic Specialization.}

The article presents the basics of professional orientation of teaching mathematics for future economists. A system of professionally oriented mathematical tasks with an economic component is proposed. It previously requires the construction of the necessary mathematical model of the process, the choice of the necessary mathematical apparatus, the method choice or the method of task solution. The functions of system of appliedoriented tasks are defined.

The necessity of applied orientation of teaching higher mathematics for students with economic specialization is validated by application of mathematical modeling, which provides both content and methodological connection between disciplines of mathematical and economic specialization.

The most prevailing are matrix models in the economy, which are successfully applied in the analysis and planning of production. Based on the theoretical propositions of analytic geometry on the plane, a mathematical model of market equilibrium is composed. The tasks of calculating marginal costs of production, marginal utility, marginal profit can be obtained from the corresponding economic functions by differentiation.

Differential equations are used in models of economic dynamics, in which both dependence of variables on time and also their interrelation in time are reflected.

The integral calculus allows the inverse task solution: to find given economic function by the known boundary

function. Since market relations are often accompanied by random phenomena and processes, factors of influence on the result of action are probabilistic.

It is proved that such an approach will promote better use of knowledge while choosing mathematical methods and constructing economic and mathematical models.

Key words: tasks with economic content, mathematical models, economic and mathematical thinking. 